SHORT COMMUNICATION

\title{
Cadmium (Cd) and Chlorpyrifos (CPF) Induced Pulmonary Toxicity in Wistar Rats
}

\author{
Ravikumar Yadala ${ }^{1 "}$, D. Madhuri ${ }^{2}$, M. Lakshman ${ }^{1}$, A. Gopala Reddy ${ }^{3}$ and B. Kalakumar ${ }^{3}$ \\ ${ }^{1}$ Department of Veterinary Pathology, C.V.Sc., PVNRTVU, Hyderabad, Telangana, INDIA \\ ${ }^{2}$ Department of Veterinary Pathology, C.V.Sc., Korutla, Jagtial Dist., Telangana, INDIA \\ ${ }^{3}$ Department of Veterinary Pharmacology and Toxicology, C.V.Sc., PVNRTVU, Hyderabad, Telangana, INDIA \\ *Corresponding author: RK Yadala; E-mail: ravikumaryadala@gmail.com
}

Received: 21 March, 2020

Revised: 08 May, 2020

Accepted: 10 May, 2020

\begin{abstract}
The present study was aimed to know the pulmonary toxicity by individual toxicities of cadmium, chlorpyrifos and their combination in albino wistar rats. The experiment was carried out for 28 days. Group 1 - Control. Group 2 - Cadmium chloride (Cd)@22.5 mg/ kg b.wt /per oral / day. Group 3 - Chlorpyrifos (CPF) @ 25 mg/ kg b.wt /per oral / day. Group 4 - Cadmium chloride (Cd)@22.5 mg + Chlorpyrifos (CPF)@ $25 \mathrm{mg} / \mathrm{kg}$ b.wt / per oral / day. Lungs showed mild to moderate congestion in groups 2 and 3 and moderate to severe in group 4 on $15^{\text {th }}$ and $29^{\text {th }}$ day of the experiment. Lung sections of control rats showed normal architecture. Lung sections of group 2 rats on $15^{\text {th }}$ day showed hemorrhages in the interstitium spaces with infiltration of lymphocytes, On $29^{\text {th }}$ day, mild hyperplasia and desquamated bronchial epithelial cells, peri bronchial and peri vascular lymphoid aggregates were noticed. The sections of lung on $15^{\text {th }}$ day of group 3 rats showed exudate and desquamated epithelial cells in the lumen of secondary bronchiole, on $29^{\text {th }}$ day, emphysematous alveoli with loss of architecture of alveolar epithelium, interstitial edema with infiltration of lymphocytes, mild hyperplasia of bronchial epithelial cells were also noticed. In group 4 rats, similar lesions as described in groups 2 and 3 were observed with severe intensity on $15^{\text {th }}$ and on $29^{\text {th }}$ day of the experiment. In combined toxicity group, the severity of lesions were more thus suggesting synergistic effects of these components.
\end{abstract}

Keywords: Pulmonary toxicity, cadmium, chlorpyrifos, Wistar rats

Cadmium (Cd) and Chlorpyrifos (CPF) are the most common toxicants among all toxic compounds in the environment. The Cd common sources of environmental contamination are industrial, mining activities, plastic stabilizers and batteries which may result in widespread into environment and agricultural fields (Cheng et al., 2011). The OP insecticides are extensively used for control of insects in home and agricultural practices. Chlorpyrifos (CPF) is one of the most commonly used organophosphate pesticides in domestic and agricultural applications throughout the world (Asperlin, 1994). Cd and $\mathrm{CPF}$ intoxication may occur directly through drinking water, indirectly through irrigation water source and through feed ingredients of plant origin and also through inhalation of polluted air. Since the population tend to receive combination of multiple intoxicants through environment contamination, there is need for conducting induced toxicopathological studies to assess the impact of individual and combined environmental pollutants (Yuan et al., 2014 and Yadala et al., 2019). Cd induces oxidative stress and apoptosis (Henson et al., 2004), CPF causes deleterious effects through acetylcholinesterase inhibition at synapse of central and peripheral nervous system (Gordon et al., 1997), thereby causing damage to various vital organs. Along with the other organs, Lungs are susceptible for environmental pollutants (Abeer et al., 2010 and Curcic et al., 2012).

How to cite this article: Yadala, Y., Madhuri, D., Lakshman, M., Reddy, A.G. and Kalakumar, B. (2020). Cadmium (Cd) and Chlorpyrifos (CPF) induced pulmonary toxicity in Wistar rats. J. Anim. Res., 10(3): 475-477. Source of Support: None; Conflict of Interest: None क्) 
The present study was focussed on pulmonary toxicity induced by $\mathrm{Cd}, \mathrm{CPF}$ and their combination in rats.

Male Wistar albino rats (48) were procured from Sanzyme Laboratories Ltd., Hyderabad, animals were divided into 4 groups, 12 animals in each group. Rats were randomly divided into 4 groups consisting of 12 in each group. Group 1 serves as control. Group 2 rats were administered Cadmium chloride $\left(\mathrm{CdCl}_{2}\right) @ 22.5 \mathrm{mg} / \mathrm{kg}$ b.wt /per oral / day. Group 3 rats were administered Chlorpyrifos (CPF)@ 25 mg/ kg b.wt /per oral / day. Group 4 rats were administered Cadmium chloride (Cd)@22.5 mg + Chlorpyrifos (CPF)@25 mg/kg b.wt/per oral / day for 28 days of experiment.

Detailed necropsy was conducted on $15^{\text {th }}$ and $29^{\text {th }}$ day of the experiment and gross changes were noticed, if any. Pieces of lung were collected in $10 \%$ neutral buffer formalin (NBF). Samples were processed, sectioned $(5 \mu \mathrm{m})$, stained with Hematoxylin and Eosin (H\&E) as per the standard protocol given (Luna, 1968).

Lungs showed mild to moderate congestion in groups 2 and 3 and moderate to severe in group 4 on $15^{\text {th }}$ and $29^{\text {th }}$ day of the experiment. Lung sections of control (Group 1) rats showed normal architecture. Lung sections of group 2 rats on $15^{\text {th }}$ day showed hemorrhages in the interstitium spaces with infiltration of lymphocytes (Fig.1A), On $29^{\text {th }}$ day, mild hyperplasia and desquamated bronchial epithelial cells, peri bronchial and peri vascular lymphoid aggregates were noticed (Fig. 1B). The present changes in the lungs might be due to $\mathrm{Cd}$ induced lipid peroxidation and oxidative stress. Similar lesions were reported by Newairy et al. (2007) and Verónica Souza Arroyo et al. (2012) in $\mathrm{CdCl}_{2}$ toxicity. The sections of lung on $15^{\text {th }}$ day of group 3 rats showed exudate and desquamated epithelial cells in the lumen of secondary bronchiole (Fig. 1C). On $29^{\text {th }}$ day, emphysematous alveoli with loss of architecture of alveolar epithelium, interstitial edema with infiltration of lymphocytes, mild hyperplasia of bronchial epithelial cells (Fig. 1D) were also noticed. Pulmonary toxic effects of CPF are mainly attributed to induction of oxidative stress and suppression of antioxidant enzyme activities. Similar changes are reported by Khan and Kour (2007) and Abbas Jafari et al. (2014). In group 4 rats, similar lesions as described in groups 2 and 3 were observed with severe intensity (Fig. 1E and $1 \mathrm{~F}$ ) on $15^{\text {th }}$ and on $29^{\text {th }}$ day of the experiment. In combined toxicity group, the severity of lesions were more thus suggesting synergistic effects of these components.

In conclusion, the adverse effects of combined $\mathrm{CdCl}_{2}$ and CPF group (Group 4) were more severe than the individual groups (Group $2 \& 3$ ) due to synergistic action of the combined pollutants.

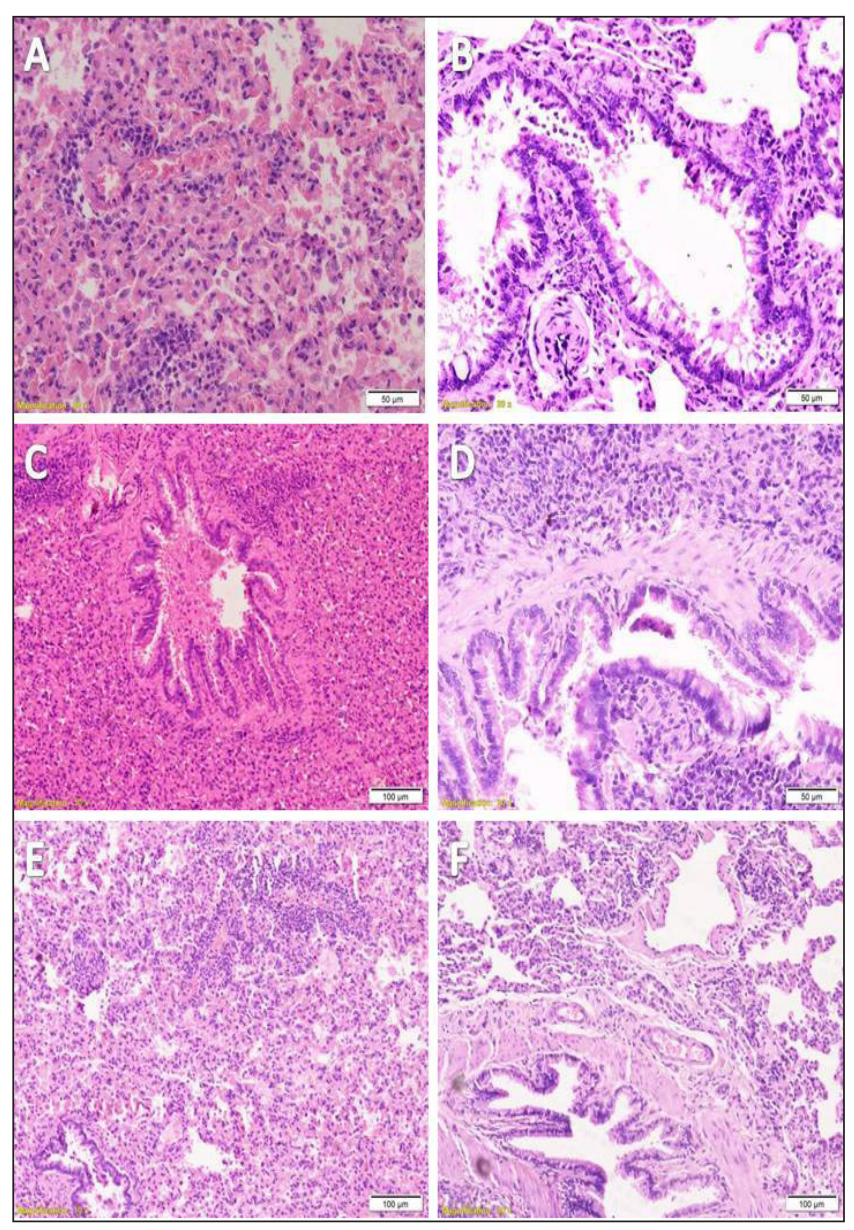

Fig. 1: Photomicrograph of lung showing (A) Hemorrhages in the interstitial spaces with infiltration of lymphocytes (Group 2, Day 15): H\&E $\times 200$; (B) Mild hyperplasia of bronchiolar epithelial cells, peri bronchial emphysema, destruction bronchiolar epithelium with infiltration of lymphocytes in peribronchiol area and interstitium (Group 2, Day 29): H\&E×200; (C) Exudate in bronchiole (Group 3, Day 15): H\&E×100; (D) Hyperplasia of bronchial epithelial cells, mild to moderate peri-bronchial fibrosis with infiltration of lymphocytes (Group 3, Day 29): H\&E $\times 200$; (E) Congestion of blood vessel, peri vascular infiltration of lymphocytes (Group 4, Day 15): H\&E×100; (F) peri bronchial fibrosis with mild hyperplasia of bronchial epithelium, peri bronchial emphysema and congestion of peri bronchial blood vessels (Group 4, Day 29): H\&E×200. 


\section{ACKNOWLEDGMENTS}

Authors were highly grateful to PVNRTVU, Rajendranagar, Hyderabad for providing facilities to carry out present case study.

\section{REFERENCES}

Cheng, C.Y., Wong, E.W. P. and Lie, P. P.Y. 2011. Environmental toxicants and male reproductive function. Spermatogenesis, 1(1): 2-13.

Asperlin, A. 1994. Pesticide industry sales and usage-1992 and 1993 market estimates. U.S. Environmental Agency report no. 733: 94-101.

Yuan, G., Dai, S., Yin, Z., Lu, H., Jia, R., Xu, J. and Zhao, X. 2014. Toxicological assessment of combined lead and cadmium: acute and sub-chronic toxicity study in rats. Food. Chem. Toxicol, 65: 260-268.

Yadala Ravikumar, Madhuri, D., Lakshman, M., Gopala Reddy, A. and Kalakumar, B. 2019. Haematological alterations induced by cadmium (Cd) and chlorpyrifos (CPF) in male Wistar albino rats. Int. J. Curr. Microbiol. App. Sci., 8(08): 480-485.

Henson, M.C. and Chedrese. P.J. 2004. Endocrine disruption by cadmium, a common environmental toxicant with paradoxical effects on reproduction. Exp. Biol. Med., 229(5): 383-392.

Gordon, C.J., Tholeatheus, A.G. and Ying, Y. 1997. Hypothermia and delayed fever in male rats exposed to chlorpyrifos. Toxicol., 118: 149-155.
Abeer Shady, M. and Fayroz Noor El-Deen, I. 2010. Effect of Chlorpyrifos on thyroid gland of adult male albino rats. Int. J. Med. Toxicol. Forensic. Med., 33(3): 441-450.

Curcic, M., Sasa, J., Vesna, J., Sanja, V., Slavika, V., Ksenija, D., Zorica, B. and Biljana, A. 2012. Combined Effects of Cadmium and Decabrominated Diphenyl ether on Thyroid hormones in rats. Arh. Hig. Rada. Toksikol., 63: 255-262.

Luna, G.L.H.T. 1968. Manual of histological and special staining techniques. $2^{\text {nd }}$ edition: The Blackstone Division McGrawHill Book Company, Inc. New York, Toronto London. 1-5: 9-34.

Newairy, A.A., El-Sharaky, A.S., Badreldeen M.M., Ewedaa S.M. and Sheweita, S.A. 2007. The hepatoprotective effects of selenium against cadmium toxicity in rats. Toxicology, 242: 23-30.

Veronica, S.A., Karina, M.F., Leticia, B.O., Luis, E.G. and Maria, C.G.R. 2012. Liver and Cadmium Toxicity. J. Drug Met. Toxicol., 5: 1-7.

Khan, S.M. and Kour, G. 2007. Subacute oral toxicity of Chlorpyrifos and protective effect of green tea extract. Pestic. Biochem. Phys., 89: 118-123.

Abbas Jafari, J., Jaafari, R., Rezaee, M., Zeinali, F., Tavakoli and Razavi-Azarkhiavi, K. 2014. Protective effects of curcumin and vitamin $\mathrm{E}$ against chlorpyrifos-induced lung oxidative damage. Hum. Exp. Toxicol., 34(6): 1-9. 